\title{
APLICAÇÃO DE UMA TÉCNICA ALTERNATIVA DE MANEJO FÍSICO DO SOLO NO CULTIVO DE Eucalyptus grandis W.Hill (Myrtaceae) ${ }^{1}$
}

\author{
João Paulo de Maçaneiro², Rafaela Cristina Seubert² e Juarês José Aumond ${ }^{3}$
}

\begin{abstract}
RESUMO - O objetivo deste estudo foi avaliar o processo de crescimento do Eucalyptus grandis quando submetido à irregularização do terreno. Baseando-se na "Ótica da Teoria do Caos" e partindo-se da hipótese de que as áreas reflorestadas por E. grandis são consideravelmente sensíveis às condições iniciais de preparação do solo, aplicou-se a técnica das rugosidades (variações do relevo alternando superfícies côncavas e convexas) para desencadear ao longo do tempo propriedades emergentes que aceleram o processo de crescimento vegetal. A área de estudo localiza-se na Bacia Hidrográfica do Rio Itajaí, em Brusque, SC. Esta foi dividida em quatro parcelas menores: duas com tratamentos irregulares (IR-A e IR-B) e outras duas com tratamentos regulares (R-A e R-B). Os tratamentos irregulares consistiram na abertura de cavas, utilizando-se uma retroescavadeira hidráulica, intercaladas com $1 \mathrm{~m}$ de largura, 4 a $5 \mathrm{~m}$ de comprimento e $0,5 \mathrm{~m}$ de profundidade. Nos tratamentos regulares foi adotado o cultivo mínimo do solo, onde o preparo do solo ficou restrito às linhas ou covas de plantio. Na análise do desenvolvimento de E. grandis (altura, diâmetro do colo e na altura do peito - DAP) verificou-se diferenças estatísticas entre as técnicas de preparação do solo, sendo os maiores valores nos tratamentos irregulares. Nas parcelas irregulares (IR-A e IR-B) foram encontrados os maiores valores médios de altura $(5,29 \mathrm{~m}$ e 5,46 m), diâmetro do colo $(45,65 \mathrm{~mm}$ e 45,4 $\mathrm{mm})$ e DAP $(4,44 \mathrm{~cm}$ e 4,79 cm), respectivamente. Pressupõe-se que as rugosidades funcionaram efetivamente como componentes auxiliares na internalização da matéria, retendo água, sedimentos e nutrientes, fato que deve ter potencializado e acelerado o crescimento do E. grandis.
\end{abstract}

Palavras-chave: Rugosidades, Preparo do solo, Eucalipto.

\section{APPLICATION OF AN ALTERNATIVE TECHNIQUE FOR PHYSICAL SOIL MANAGEMENT IN CULTIVATION OF Eucalyptus grandis W.Hill (Myrtaceae)}

\begin{abstract}
The aim of this study was to evaluate the process of growth of Eucalyptus grandis non-regularization when subjected to the ground. Relying on "Optical Chaos Theory" and starting from the assumption that the reforested areas by $\boldsymbol{E}$. grandis are considerably sensitive to the initial conditions of soil preparation was applied the technique of roughening (variations relief alternating concave and convex surfaces) to cause over time emergent properties that accelerate the process of plant growth. The study area is located on the Itajai River Basin, in Brusque, SC. This was divided into four smaller portions: two treatments with irregular (IR-A and IR-B) and two others with regular treatments ( $R-A$ and $R-B)$. The treatments consisted of irregular armhole opening, using a hydraulic backhoe, interspersed with 1 meter wide, 4 to 5 meters long and 0.5 meters deep. In regular treatments was adopted minimum tillage of the soil, where soil preparation was restricted to lines or planting holes. In the analysis of the development of $\boldsymbol{E}$. grandis (height, diameter and breast height - DBH) was found statistical differences between the techniques of soil preparation, and the highest values in treatments irregular. In plots irregular (IR-A and IR-B) were found higher mean values of height (5.29 meters and 5.46 meters), stem diameter (45.65 mm and $45.4 \mathrm{~mm})$ and DBH (4.44 cm to
\end{abstract}

\footnotetext{
${ }^{1}$ Recebido em 14.12.2011 aceito para publicação em 17.01.2013.

${ }^{2}$ Departamento de Engenharia Florestal da Universidade Regional de Blumenau -FURB, Blumenau, SC. E-mail: <jpmacaneiro@gmail.com> e <rc.seubert@gmail.com>.

${ }^{3}$ Departamento de Ciências Naturais da Universidade Regional de Blumenau - FURB, Blumenau, SC. E-mail: <aumond@ furb.br>.
} 
$4.79 \mathrm{~cm})$, respectively. It is assumed that the roughness effectively functioned as auxiliary components in the internalization of matter, retaining water, sediments and nutrients, a fact that should have enhanced and accelerated the growth of $\boldsymbol{E}$. grandis.

Keywords: Roughness, Soil preparation, Eucalyptus.

\section{INTRODUÇÃO}

Desde a introdução de espécies exóticas para fins energéticos, dormentes, polpa e papel, o setor florestal brasileiro vem se desenvolvendo e ampliando as suas áreas de plantio. A demanda sempre crescente por produtos oriundos das florestas plantadas resultou na ampliação do mercado florestal brasileiro, e consequentemente, na preservação dos recursos provindos de florestas nativas (LOPES et al., 2004; TREVISAN et al., 2007).

O eucalipto (Eucalyptus spp.) é uma destas espécies introduzidas, tendo sua origem na Austrália, Indonésia e ilhas próximas, tais como Flores, Alor e Wetar. O gênero Eucalyptus, pertencente à família Myrtaceae, possui cerca de 600 espécies e sub-espécies, e apresenta uma ampla plasticidade e dispersão mundial, crescendo satisfatoriamente em diferentes situações edafoclimáticas, extrapolando aquelas das regiões de origem (SANTOS et al., 2001). Dentre as inúmeras espécies arbóreas existentes no mundo, o eucalipto, devido à sua ampla diversidade de espécies, às características de rápido crescimento, alta produtividade, capacidade de adaptação e diferentes aplicações, tem sido extensivamente utilizado em plantios florestais no Brasil (MORA; GARCIA, 2000).

Por outro lado, a perda de solo consequente do escoamento superficial em plantações florestais é um fator ambiental negativo para o manejo e conservação destes solos. Isso se deve não apenas às perdas de nutrientes e de matéria orgânica, causadas principalmente pela erosão hídrica, mas também pela perda do próprio solo, que é um processo degradante irreversível (GUERRA et al., 1999; GONÇALVES; STAPE, 2002; MARTINS et al., 2003; BERTOL et al., 2006).

O presente estudo trata de um experimento comparativo entre o modelo tradicional de preparação do solo (cultivo mínimo) e o modelo de irregularização do terreno (técnica das rugosidades).

Revista Árvore, Viçosa-MG, v.37, n.1, p.09-18, 2013
O modelo alternativo aqui proposto já foi utilizado com sucesso por Aumond (2007) e Aumond et al. (2012) na recuperação de áreas degradadas por mineração de argila. Trata-se da consorciação de superfícies convexas e côncavas (rugosidades), que geram a internalização das variáveis ecológicas, desencadeando ao longo do tempo propriedades emergentes que aceleram o processo de crescimento vegetal e influenciam positivamente as variáveis bióticas e abióticas aumentando significativamente a conservação da água e do solo (AUMOND, 2003, 2007, 2009; AUMOND et al., 2012), na “Ótica da Teoria do Caos" de Lorenz (1996), e na Engenharia de Sistemas de Daenzer e Huber (1994) tratou-se a área de pesquisa como um sistema dinâmico complexo, hipersensível às condições iniciais de preparação do solo.

Neste trabalho partiu-se da hipótese de que as áreas reflorestadas com E. grandis são sensíveis às condições iniciais de preparação do solo e que quando submetidas à aplicação da técnica das rugosidades irão desencadear ao longo do tempo, propriedades emergentes que acelerem o processo de crescimento das árvores.

\section{MATERIAL E MÉTODOS}

\subsection{Caracterização da área de estudo}

A área de estudo está localizada na Bacia Hidrográfica do Rio Itajaí, em Brusque, SC. Situa-se em uma fazenda da empresa Buettner S/A utilizada com reflorestamentos de Eucalyptus grandis em uma altitude aproximada de 85 metros s.n.m. (27²' 42,4" S e 48 54' 29,6" O). O clima do município de Brusque segundo classificação de Köppen é do tipo Cfa-clima subtropical mesotérmico úmido com verão quente. Sua temperatura média anual varia de 19 a $20^{\circ} \mathrm{C}$ com médias mensais variando entre $15^{\circ} \mathrm{C}$ no mês de julho e $25^{\circ} \mathrm{C}$ nos meses de janeiro e fevereiro. A precipitação total anual varia de 1.700 a $1.900 \mathrm{~mm}$ e a umidade relativa anual de 84 e $86 \%$ (EPAGRI, 2002). 
A geologia da região é formada pelo Complexo Metamórfico Brusque, que é composto principalmente pela Formação Botuverá (filitos e xistos), pelo Granodiorito Valsungana e pelo Granito Guabiruba (GAPLAN, 1986; EMBRAPA, 1998). Predomina na região de estudo oARGISSOLOVERMELHO-AMARELOAlíco de textura média argilosa (EMBRAPA, 2004).

\subsection{Preparo do solo e plantio das mudas}

A área total do experimento tem $4.720 \mathrm{~m}^{2} \mathrm{e}$ foi dividida em quatro parcelas menores, duas com $1.120 \mathrm{~m}^{2}$ (R-A e IR-A) e as outras duas com $1.240 \mathrm{~m}^{2}$ (R-B e IR-B). Após delimitação das parcelas, foram criadas rugosidades e modificado a morfologia do terreno nas parcelas IR-A e IR-B. Nas parcelas R-A e R-B foram adotados o cultivo mínimo, onde o preparo do solo ficou restrito às linhas ou covas de plantio, mantendo os resíduos culturais sobre o terreno (GONÇALVES et al., 1999).

As rugosidades foram criadas paralelamente às curvas de nível e equidistantes umas das outras em cerca de 3 a 4 metros. A distribuição linear das rugosidades é importante para que não interfira na circulação de pessoas entre as linhas de plantio e que permita o livre trânsito dos equipamentos durante o corte da madeira na fase de colheita. Elas foram criadas utilizando-se retroescavadeira hidráulica, sendo realizadas cavas com $0,8 \mathrm{~m}$ de largura (correspondente à largura da concha da retroescavadeira), 4 a $5 \mathrm{~m}$ de comprimento e $0,5 \mathrm{~m}$ de profundidade. As rugosidades foram criadas espacialmente defasadas, de forma que o intervalo entre uma e outra na linha acima corresponda a uma rugosidade na linha abaixo. Essa defasagem entre rugosidades de cotas diferentes funciona como uma armadilha, impedindo o escoamento de água, sedimentos e nutrientes, minimizando o efeito do comprimento do pendente no escoamento da água. Esse método internaliza no sistema água, sedimentos e nutrientes, disponibilizando-os para as plantas ao longo do tempo (BERTOL et al., 2006; AUMOND, 2007; MOSER et al., 2009; AUMOND et al., 2012).

Após o preparo das rugosidades, foram selecionadas 1.180 mudas da espécie $E$. grandis e realizado o plantio nas áreas. Tanto para as parcelas regulares (R-A e R-B) como para as irregulares (IR-A e IR-B) as mudas foram plantadas com espaçamento de 2 x 2 m conforme Schönau (1984) e Leite et al. (1997). Dentro das rugosidades não foi realizado o plantio das mudas. Nas parcelas IR-A e R-A foram plantados 280 mudas cada e nas parcelas IR-B e R-B foram plantados 310 mudas em cada parcela.

\subsection{Coleta e análise das variáveis bióticas e abióticas}

Para as medições da umidade relativa do ar e radiação solar, foi instalado na área do experimento um sistema de aquisição de sinais acoplado a um microcomputador tipo netbook. Os sensores foram gerenciados por uma aparelhagem de hardware e pelo programa Projeto Climus, desenvolvido no Laboratório de Meios Porosos e Propriedades Termofísicas dos Materiais (LMPT) da Universidade Federal de Santa Catarina e adaptado especialmente para esta pesquisa.

Nos meses de dezembro do primeiro e segundo ano de implantação do experimento, durante um período de dois dias o sistema de aquisição de sinais acoplado ao netbook fez o registro contínuo das variáveis abióticas em cada parcela, calculando automaticamente as médias, a cada hora e remetendo-as para um arquivo.

As medidas de umidade relativa do ar foram registradas com dois sensores de umidade do tipo capacitivo, com incerteza de $0,5 \%$. Os sensores foram instalados a 1,3 metros de altura do solo, conectados ao computador netbook, sendo um para cada parcela do experimento.

A radiação solar de todo o espectro eletromagnético foi medido por dois sensores do tipo termo-elementos com incerteza de 5\%. Estes sensores foram instalados próximos dos sensores de umidade relativa do ar e realizaram as medidas automaticamente $\mathrm{em} \mathrm{W} / \mathrm{m}^{2}$ para cada parcela do experimento.

Para quantificação das variáveis bióticas, em cada uma das quatro parcelas do experimento foram selecionados aleatoriamente 60 indivíduos de $E$. grandis onde foram medidos o diâmetro à altura do peito (DAP), diâmetro do colo a $5 \mathrm{~cm}$ do solo e a altura total.

O tratamento estatístico dos dados foi realizado para as quatro parcelas do experimento, considerando-as como quatro tratamentos diferentes, onde cada tratamento continha 60 repetições. Os valores médios das variáveis bióticas e abióticas entre os tratamentos foram submetidos à análise de variância e suas médias comparadas a partir do teste de Tukey com nível de significância $\alpha=0,05$ (ZAR, 1999).

Revista Árvore, Viçosa-MG, v.37, n.1, p.09-18, 2013

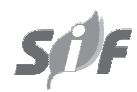




\section{RESULTADOS}

\subsection{Variáveis bióticas}

$\mathrm{Na}$ análise da variável altura total dos indivíduos de E. grandis se encontrou diferença estatística $(p<0,05)$ entre os tratamentos IR-A e R-A nos três períodos de avaliações. Para os tratamentos IR-B e R-B encontrou-se diferença estatística apenas na medição realizada em dezembro de 2010 (Tabela 1). A comparação das medidas de altura média dos indivíduos das áreas irregulares e regulares nos três períodos de avaliações (dezembro de 2009, junho de 2010 e dezembro de 2010) evidenciou um crescimento expressivamente maior nos tratamentos irregulares (Figura 1a).

Após quatro e nove meses do plantio, os indivíduos nos tratamentos irregulares apresentaram incremento em diâmetro do colo estatisticamente superior $(p<0,05)$ quando comparados aos tratamentos regulares (Tabela 1 e Figura 1b). Os maiores valores em diâmetro do colo após nove meses de plantio foram encontrados nos tratamentos irregulares (IR-A e IR-B) que acusaram 45,65 $\mathrm{mm}$ e 45,40 mm, respectivamente.
As medidas do DAP, quantificadas 15 meses após o plantio, foram maiores nos tratamentos irregulares quando comparadas com os regulares. Encontrou-se diferença estatística $(p<0,05)$ nas medidas entre os tratamentos IR-A e R-A e nos tratamentos IR-B e R-B no período de dezembro de 2010 (Tabela 1). Na Figura 1c pode-se observar o aumento do DAP no período avaliado.

\subsection{Variáveis abióticas}

A análise dos dados referentes à radiação solar nos meses de dezembro de 2009 e dezembro de 2010 evidenciou o efeito das plantas na incidência da radiação nos quatro tratamentos (IR-A, R-A, IR-B e R-B). Verificou-se um aumento da diferença na radiação entre os tratamentos regulares e irregulares ao longo do tempo, seguindo uma tendência definida pelo crescimento das plantas (Tabela 2) de forma que a radiação nos tratamentos irregulares é menor desde dezembro de 2009, após um ano de medições do experimento. Neste período a média da radiação nos tratamentos irregulares variou de 156,9 a $426 \mathrm{~W} / \mathrm{m}^{2}$ enquanto nos tratamentos regulares variou de 210 a $430,3 \mathrm{~W} / \mathrm{m}^{2}$. No entanto, não foi obtida diferenciação estatística $(p>0,05)$ pelo teste de Tukey entre os tratamentos.

Tabela 1 - Medições das variáveis bióticas: altura total; diâmetro do colo e diâmetro à altura do peito de E. grandis referente ao período de $12 / 2009$ a 12/2010. As médias seguidas pela mesma letra, entre as medições do mesmo ano, não diferem estatisticamente entre si ao nível de significância $\alpha=0,05$ pelo teste de Tukey.

Table 1 - Measurements of biotic variables: total height, diameter and diameter at breast height of $\boldsymbol{E}$. grandis for the period from 12/2009 to 12/2010. Means followed by the same letter, between measurements of the same year, not statistically different from each other at a significance level $\alpha=0.05$ by Tukey test.

\begin{tabular}{|c|c|c|c|}
\hline \multirow{2}{*}{ Parcelas } & \multicolumn{3}{|c|}{ Altura total $(\mathrm{m})$} \\
\hline & Dez/2009 & Jun/2010 & Dez/2010 \\
\hline IR-A & 1,15 a $( \pm 0,07)$ & 3,88 a $( \pm 0,25)$ & 5,29 a $( \pm 0,38)$ \\
\hline $\mathrm{R}-\mathrm{A}$ & 0,99 b $( \pm 0,07)$ & 3,07 b $( \pm 0,25)$ & 4,04 b $( \pm 0,37)$ \\
\hline IR-B & $1,04 \mathrm{ab}( \pm 0,05)$ & $3,35 \mathrm{~b}( \pm 0,23)$ & 5,46 a $( \pm 0,34)$ \\
\hline \multirow[t]{3}{*}{ R-B } & $0,99 \mathrm{~b}( \pm 0,05)$ & $3,01 \mathrm{~b}( \pm 0,19)$ & $4,11 \mathrm{~b}( \pm 0,29)$ \\
\hline & \multicolumn{3}{|c|}{ Diâmetro do colo (mm) } \\
\hline & Dez/2009 & Jun/2010 & \\
\hline IR-A & $15,85 \mathrm{~b}( \pm 1,00)$ & 45,65 a $( \pm 2,80)$ & \\
\hline $\mathrm{R}-\mathrm{A}$ & $13,67 \mathrm{c}( \pm 0,98)$ & 37,63 b $( \pm 3,19)$ & \\
\hline IR-B & 18,54 a $( \pm 0,91)$ & 45,40 a $( \pm 2,80)$ & \\
\hline \multirow[t]{3}{*}{$\mathrm{R}-\mathrm{B}$} & $13,78 \mathrm{c}( \pm 0,84)$ & 38,71 b $( \pm 2,71)$ & \\
\hline & \multicolumn{3}{|c|}{ Diâmetro à altura do peito $(\mathrm{cm})$} \\
\hline & Jun/2010 & & Dez/2010 \\
\hline IR-A & 3,01 a $( \pm 0,25)$ & & 4,44 a $( \pm 0,41)$ \\
\hline $\mathrm{R}-\mathrm{A}$ & $2,21 \mathrm{~b}( \pm 0,27)$ & & 3,06 b $( \pm 0,37)$ \\
\hline IR-B & $2,66 \mathrm{ab}( \pm 0,27)$ & & 4,79 a $( \pm 0,36)$ \\
\hline $\mathrm{R}-\mathrm{B}$ & $2,33 \mathrm{~b}( \pm 0,26)$ & & $3,50 \mathrm{~b}( \pm 0,28)$ \\
\hline
\end{tabular}

Revista Árvore, Viçosa-MG, v.37, n.1, p.09-18, 2013 

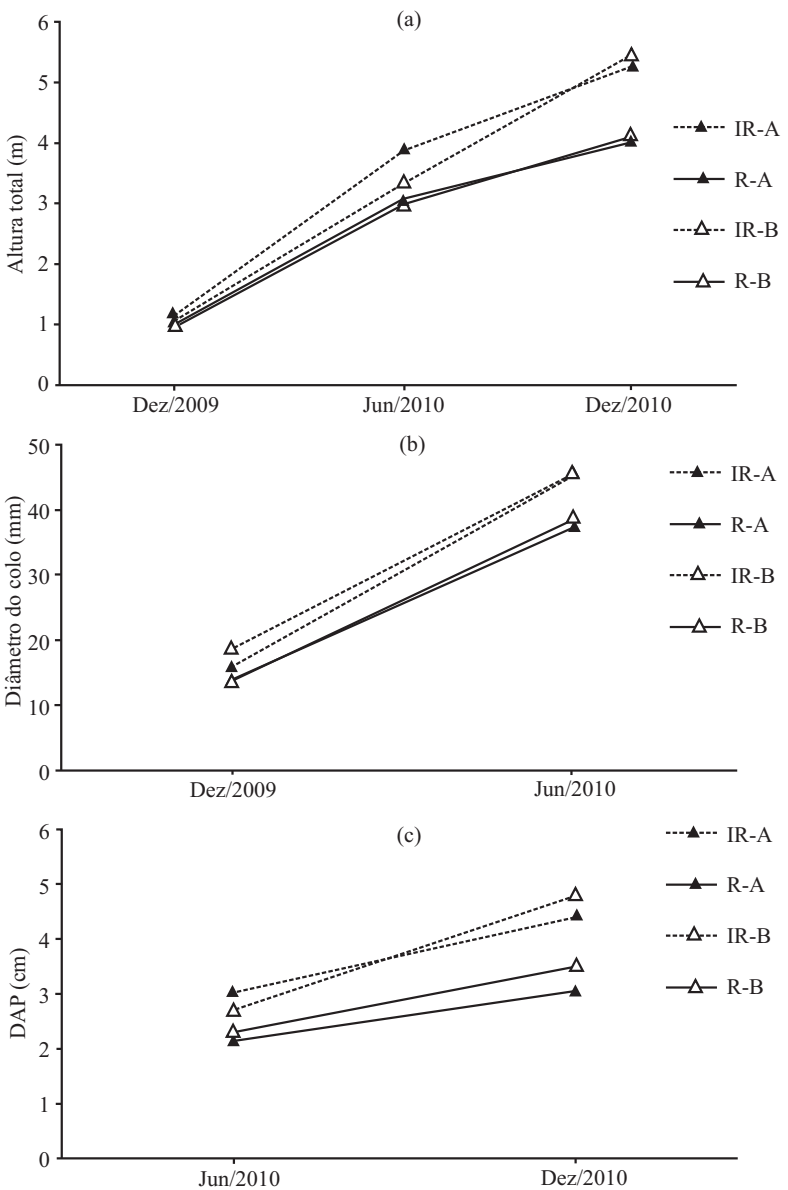

Figura 1 - Medições das variáveis bióticas: altura total (a); diâmetro do colo (b); e diâmetro à altura do peito (c) de E. grandis referente ao período de 12/2009 a $12 / 2010$

Figure 1-Measurements of biotic variables: total height (a), diameter (b) and diameter at breast height (c) of E. grandis for the period from 12/2009 to 12/2010.

Nas medições realizadas entre os dias 21 e 23 de dezembro de 2009 , as radiações variaram no período da tarde de $1.530 \mathrm{~W} / \mathrm{m}^{2}$ para o dia 21 até mais de 400 $\mathrm{W} / \mathrm{m}^{2}$ para o dia 23 nas parcelas IR-A e R-A (Figura 2a). Quanto aos tratamentos IR-B e R-B, predominaram picos de radiação acima de $800 \mathrm{~W} / \mathrm{m}^{2}$ no tratamento regular (R-B), e com certa frequência os picos ultrapassaram os $450 \mathrm{~W} / \mathrm{m}^{2}$ no período da tarde nos tratamentos IR-B e R-B (Figura 2b). A maior radiação solar nos tratamentos regulares se deve ao menor crescimento de E. grandis nessas áreas. A pequena radiação acima de $30 \mathrm{~W} / \mathrm{m}^{2}$ observada no período noturno se deve a luz dispersada por residências nas redondezas da área de pesquisa.
Nas medições realizadas no dia 15 de dezembro de 2010, o pico de radiação ultrapassou $1.200 \mathrm{~W} / \mathrm{m}^{2}$ no tratamento regular (R-A) e $450 \mathrm{~W} / \mathrm{m}^{2}$ no irregular (IR-A). Entre os dias 14 e 16 de dezembro de 2010 as radiações nos tratamentos regulares também foram superiores, se comparadas com os dos tratamentos irregulares, podendo mais do que duplicar, como no caso do dia 15 (Figura 2c). No entanto, a partir de 14 de dezembro de 2010, os valores das medições para radiação solar foram maiores nos tratamentos regulares (R-A e R-B) quando comparados aos irregulares (IR-A e IR-B) (Figura 2d).

Através das medições de umidade relativa do ar (\%) nos tratamentos regulares e irregulares verificaram-se pequenas diferenças entre as mesmas. Nas Figuras 3a, 3c e 3d pode-se observar que ao amanhecer o ar ainda está saturado (100\% de umidade relativa), quando então começa a cair a umidade, atingindo os valores mínimos por volta do meio da tarde, quando a radiação atinge os seus níveis máximos. No entardecer, quando a radiação solar diminui, a umidade relativa do ar aumenta progressivamente até atingir a saturação (100\%) e assim permanece durante toda a noite. No entanto, constatou-se que nas medições de dezembro de 2010 houve um aumento da umidade relativa do ar nos tratamentos irregulares, isso se deve ao maior desenvolvimento dos indivíduos, resultando em menor radiação solar nessas áreas (Tabela 2).

Na Figura 3b pode-se observar uma variação constante na umidade relativa do ar nos tratamentos IR-B e R-B no período de 23 a 25 de dezembro de 2009 , estes valores podem ter sido influenciados pelos ventos e chuvas de verão que ocorreram no período das medições. Com o vento e chuva constantes observados em campo, as nuvens se movimentam rapidamente, fazendo com que ocorra um aumento e diminuição bruscos do sombreamento na área da pesquisa, influenciando diretamente na quantidade de radiação no interior do plantio e, consequentemente, na umidade relativa do ar. Nas Figuras 3c e 3d pode-se observar que há diferença entre os valores de umidade relativa do ar encontrados nos tratamentos irregulares (IR-A e IR-B) e regulares (R-A e R-B) no período de 14 a 18 de dezembro de 2010, no entanto, não encontrou-se diferenciação estatística pelo teste de Tukey $(p>0,05)$.

Revista Árvore, Viçosa-MG, v.37, n.1, p.09-18, 2013 
Tabela 2 - Medições das variáveis abióticas: radiação solar e umidade relativa do ar na área experimental, referente ao período de 21 à 23/12/2009 e 23 à 25/12/2010. As médias seguidas pela mesma letra, entre as medições do mesmo ano, não diferem estatisticamente entre si ao nível de significância $\alpha=0,05$ pelo teste de Tukey.

Table 2 - Measurements of abiotic variables: solar radiation and relative humidity in the experimental area, relative to $12 / 21 / 2009$ to 12/23/2009 and 12/23/2010 to 12/23/2010. Means followed by the same letter, between measurements of the same year, not statistically different from each other at a significance level $\alpha=0.05$ by Tukey test.

\begin{tabular}{|c|c|c|}
\hline \multirow{2}{*}{ Período de avaliação } & \multicolumn{2}{|c|}{ Radiação Solar (W/m²) } \\
\hline & IR-A & $\mathrm{R}-\mathrm{A}$ \\
\hline 21 à 23/12 de 2009 & 426,0 a $( \pm 122,8)$ & 430,3 a $( \pm 115,1)$ \\
\hline \multirow[t]{2}{*}{14 à $16 / 12$ de 2010} & $200,1 \mathrm{ab}( \pm 36,8)$ & 287,6 a $( \pm 88,4)$ \\
\hline & IR-B & R-B \\
\hline 23 à 25/12 de 2009 & 250,3 a $( \pm 53,5)$ & 308,8 a $( \pm 72,5)$ \\
\hline \multirow[t]{2}{*}{16 à $18 / 12$ de 2010} & 156,9 b $( \pm 20,1)$ & $210,0 \mathrm{ab}( \pm 41,3)$ \\
\hline & \multicolumn{2}{|c|}{ Umidade Relativa do Ar (\%) } \\
\hline & IR-A & $\mathrm{R}-\mathrm{A}$ \\
\hline 21 à 23/12 de 2009 & 79,9 a $( \pm 4,4)$ & 83,1 a $( \pm 5,3)$ \\
\hline 14 à $16 / 12$ de 2010 & 87,9 ab $( \pm 4,8)$ & 83,6 b $( \pm 5,4)$ \\
\hline & IR-B & R-B \\
\hline 23 à 25/12 de 2009 & 86,9 a $( \pm 1,7)$ & 85,7 a $( \pm 2,1)$ \\
\hline 16 à $18 / 12$ de 2010 & 92,9 a $( \pm 2,1)$ & 91,6 a $( \pm 3,1)$ \\
\hline
\end{tabular}

\section{DISCUSSÃO}

\subsection{Variáveis bióticas}

As médias de crescimento em altura do E. grandis aos 15 meses após o plantio nos dois tratamentos irregulares foram estatisticamente superiores $(p<0,05)$ quando comparados aos tratamentos regulares, este fato reflete o efeito das rugosidades do solo no crescimento das árvores. O valor da altura média $(5,37 \mathrm{~m})$ para os tratamentos irregulares foram superiores quando comparados aos de Mello et al. (2009), em São Francisco de Assis - RS, que em 12 meses de plantio acusaram altura média de $1,38 \mathrm{~m}$ para mudas de E. grandis micorrizadas. Os tratamentos irregulares do presente estudo também apresentaram alturas superiores aos trabalhos desenvolvidos em Capão Bonito, SP por Silveira et al. (2004), que em nove meses de plantio registraram altura média de 2,34 m para espécies de Eucalyptus spp..

Semelhante a variável altura total, o diâmetro à altura do peito médio registrado nos tratamentos irregulares $(4,62 \mathrm{~cm})$ foi estatisticamente superior $(p<0,05)$ aos tratamentos regulares $(3,28 \mathrm{~cm})$. Estudos realizados por Mello et al. (2009) registraram médias de DAP para E. grandis entre 1,0 e 2,2 cm após 12 meses de observações. Finger et al. (1996) encontraram médias no DAP em $E$. grandis de 3,78 cm após 24 meses de observações.

Revista Árvore, Viçosa-MG, v.37, n.1, p.09-18, 2013
Prevedello (2008) verificou que quanto maior a intensificação no preparo do solo, melhor será o desenvolvimento das mudas de E. grandis. Este fato corrobora com os resultados obtidos no presente estudo, onde a criação das rugosidades no solo proporcionou um aumento no crescimento do E. grandis.

Solos com presença de rugosidades mantém uma melhor capacidade de retenção e infiltração superficial de água quando comparados a solos com superfície lisa (CASTRO et al., 2006), refletindo na diminuição do escoamento superficial e na deposição de sedimentos erodidos (BERTOL et al., 1989). Moser et al. (2009) constataram uma correlação entre a concentração de nutrientes e o aumento da superfície rugosa em áreas sobre processo de restauração nas Florestas Pantanosas da Virginia, EUA. Neste sentido, as rugosidades do solo além de internalizarem parte da água, sedimentos e nutrientes, podem estar favorecendo o crescimento do E. grandis (AUMOND; MAÇANEIRO, no prelo).

\subsection{Variáveis abióticas}

A radiação solar, ao incidir nas áreas irregulares, é drasticamente reduzida pelas copas das árvores, à medida que ocorre o fechamento do dossel. Esse processo é descrito por Andrade et al. (2002), que avaliando a transmissão de luz em sistemas silvipastoris com eucalipto, verificaram que as árvores de 

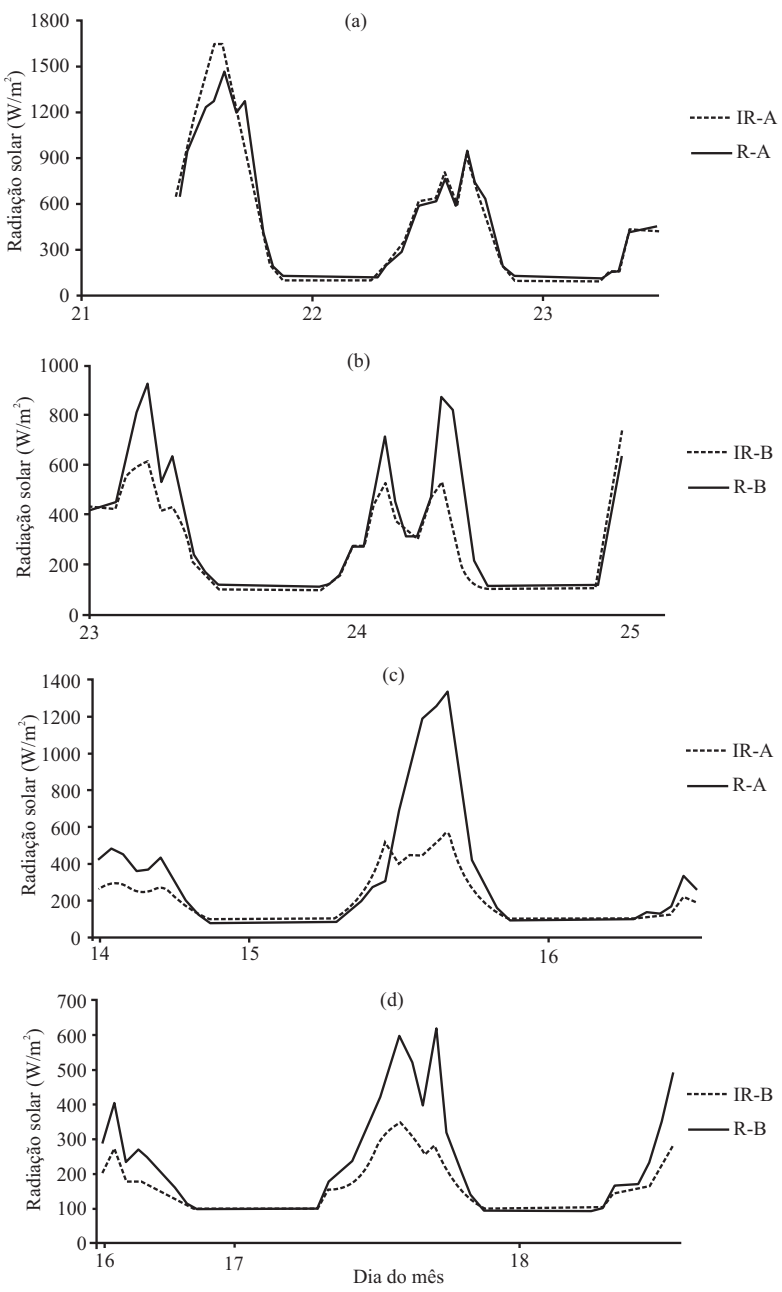

Figura 2 - Medições da variável abiótica: radiação solar $\left(\mathrm{W} / \mathrm{m}^{2}\right)$ referente aos tratamentos irregulares e regulares no período de 21 a 25 de dezembro de 2009 ("a" e "b") e 14 a 18 de dezembro de 2010 ("c"e "d").

Figure 2-Measurements of abiotic variable: solar radiation $\left(\mathrm{W} / \mathrm{m}^{2}\right)$ for the irregular and regular treatments from 21 to 25 December 2009 (" $a$ " and " $b$ ") and 14 to 18 December 2010 ( "c" and "d").

povoamentos com 2,5 anos apresentaram copas menores, porém mais densas, influenciando diretamente na radiação solar.

O maior desenvolvimento dos indivíduos de E. grandis nos tratamentos irregulares (IR-A e IR-B) provoca maior sombreamento no interior do plantio, que resulta em menor incidência de radiação no estrato abaixo das copas em comparação com os tratamentos

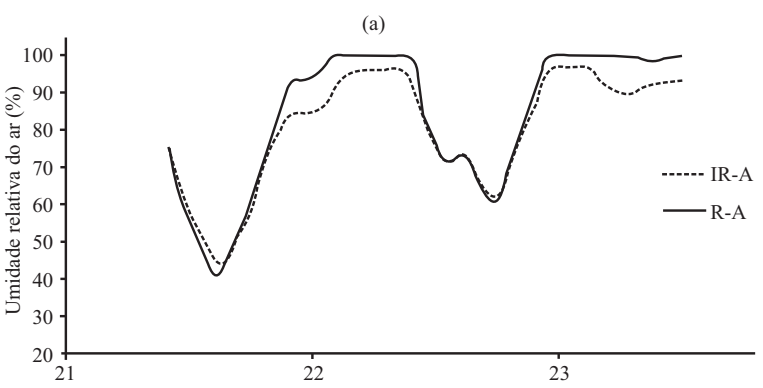

(b)
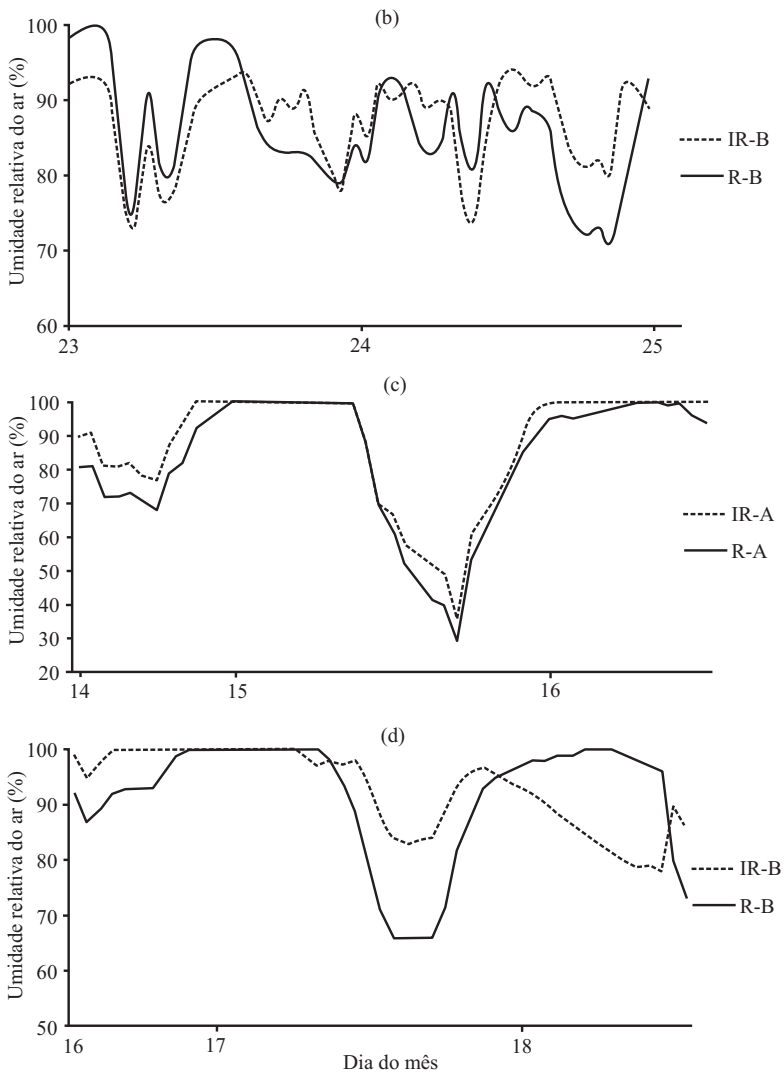

Figura 3 - Medições da variável abiótica: umidade relativa do ar (\%) referente aos tratamentos irregulares e regulares no período de 21 a 25 de dezembro de 2009 ("a" e "b") e 14 a 18 de dezembro de 2010 ("c" e "d").

Figure 3- Measurements of abiotic variable: relative humidity (\%) related to irregular and regular treatments from 21 to 25 December 2009 ( " $a$ " and " $b$ ") and 14 to 18 December 2010 ( “c” and “d”).

regulares (R-A e R-B). As quedas bruscas de radiação, registradas nos gráficos, durante o dia, resultam do efeito da passagem das nuvens que projetam suas sombras sobre a área de pesquisa. Oliveira et al. (2007)

Revista Árvore, Viçosa-MG, v.37, n.1, p.09-18, 2013 
estudando a variação da radiação solar entre as linhas e entrelinhas de plantio de Eucalyptus spp., registraram um sombreamento mais homogêneo no povoamento, tanto nas linhas como nas entrelinhas, devido à proximidade e o avanço do fechamento das copas pelo crescimento das árvores.

Quando são analisadas as Figuras 2c e 2d, percebe-se mais facilmente que a curva da radiação nos tratamentos irregulares é inferior durante o dia como reflexo do efeito da proteção desenvolvida pela maior superfície de copa dos indivíduos de E. grandis. Em compensação, à noite a perda de energia acumulada é menor. Este fator é relevante para a amenização da temperatura do ambiente e do solo, reduzindo assim o consumo de água pelas plantas através da evapotranspiração. $\mathrm{Na}$ presente pesquisa, ficou evidente que a relação entre os indivíduos de E. grandis e a radiação solar, não é uma relação linear simples, mas tem um efeito de retro-alimentação em que ambos interagem mutuamente de forma complexa, dinâmica e heterogênea ao longo do processo de crescimento vegetal.

Nas medidas realizadas em dezembro de 2010, observou-se uma maior variabilidade na umidade relativa do ar (Figuras 3c e 3d). Em alguns momentos do dia há maior umidade relativa do ar nos tratamentos irregulares. Este fato reflete as mudanças anteriormente já constatadas nesse período, na intensidade da radiação solar, resultante do crescimento diferenciado dos indivíduos de E. grandis nos tratamentos, que se expressa numa maior amenização das condições climáticas no interior do plantio. Nascimento et al. (2010) constataram um aumento da umidade relativa do ar de acordo com o crescimento e expansão das copas do eucalipto, propiciando em poucos meses de idade um intenso sombreamento do solo e atenuação dos ventos no interior dos povoamentos.

A arquitetura das copas nas árvores regula várias características abióticas como luz, temperatura, ventos e umidade sob o dossel, evidenciando que a estrutura do dossel das florestas é um resultado complexo e dinâmico das interações fisiológicas e evolutivas entre a vegetação e o ambiente (SCHUMACHER; POGGIANI, 1993).

Observou-se que nos plantios de E. grandis ocorre um desencadeamento de uma teia complexa de interações entre o meio biótico e o abiótico, onde o maior desenvolvimento dos indivíduos ameniza as condições

Revista Árvore, Viçosa-MG, v.37, n.1, p.09-18, 2013 microclimáticas (radiação solar e umidade relativa do ar), e que pode ser um fator positivo para o desenvolvimento da espécie em um plantio florestal.

\section{CONCLUSÕES}

As análises permitem concluir que o comportamento das árvores nas parcelas experimentais evoluiu de forma diferenciada nos tratamentos regulares e irregulares. Pressupõe-se que as rugosidades, como único diferencial entre os dois tratamentos, funcionaram efetivamente como componentes auxiliares na internalização da matéria, retendo água, sedimentos e nutrientes, confirmando a tese de Aumond (2007), fato que deve ter potencializado e acelerado o crescimento do E. grandis. Supõe-se ainda, que os tratamentos regulares se comportaram como superfícies dissipadoras de matéria e energia, gerando maior escoamento para fora do sistema e, consequentemente, disponibilizando menor quantidade de água, solo e nutrientes nestas áreas quando comparadas com os tratamentos irregulares.

As variáveis bióticas analisadas para E. grandis (altura, diâmetro do colo e DAP) apresentaram um crescimento expressivamente maior nos tratamentos irregulares, podendo ser considerado como resultado das rugosidades que aceleraram o crescimento do $E$. grandis pela maior disponibilidade de água, solo e nutrientes.

As menores radiações nos tratamentos irregulares promovidas pelo aumento do crescimento das árvores provocaram uma tendência para maior umidade relativa do ar. Nos períodos de chuva, constatou-se no campo a presença de água retida nas rugosidades. As superfícies côncavas das rugosidades exerceram importante papel na retenção da água podendo resultar numa maior umidade local no solo. Esse fato é importante quando tratamos de longos períodos de estiagem que podem ocorrer no decorrer do ciclo de plantio, onde as rugosidades teriam um papel fundamental na disponibilidade de água para as plantas e na minimização dos processos erosivos.

Supõe-se que os tratamentos regulares se comportaram como superfícies dissipadoras de matéria e energia e as precipitações geraram maior escoamento para fora do sistema, desencadeando maior perda de nutrientes do solo. Diferente do encontrado nos tratamentos irregulares, onde as rugosidades propiciaram erosão e lixiviação nas formas convexas e, consequentemente, um correspondente direto de sedimentação e retenção nas concavidades do plantio. 
Com os resultados obtidos nesta pesquisa, comprova-se que a técnica das rugosidades aplicada em recuperação de áreas degradadas por mineração de argila descrita por Aumond (2007) tem também efeitos positivos no incremento da produção de E. grandis.

\section{REFERÊNCIAS}

ANDRADE, C. M. S. et al. Transmissão de luz em sistemas silvipastoris com eucalipto. Revista Árvore, v.26, n.1, p.19-23, 2002.

AUMOND, J. J. Teoria dos sistemas: uma nova abordagem para recuperação e restauração ambiental. In: SIMPÓSIO BRASILEIRO DE ENGENHARIA AMBIENTAL, 2003, Itajaí. Anais... Itajaí: UNIVALI, 2003. p.10-16.

AUMOnd, J. J. Adoção de uma nova abordagem para recuperação de área degradada pela mineração. 2007. 265 f. Tese (Doutorado em Engenharia Civil) Universidade Federal de Santa Catarina, Florianópolis, 2007.

AUMOND, J. J. Reflexões sobre a necessidade de uma nova abordagem na reconstrução dos ecossistemas degradados. In: TRES, D. R.; REIS, A. Perspectivas sistêmicas para a conservação e restauração ambiental: do pontual ao contexto. Itajaí: Herbário Barbosa Rodrigues, 2009. p.45-60.

AUMOND, J. J.; MAÇANEIRO, J. P. Abordagem sistêmica e aplicação de rugosidades para desencadear propriedades emergentes em restauração de solos degradados. Ciência Florestal, 2012 (no prelo).

AUMOND, J. J. et al. Abordagem sistêmica e o uso de modelos para recuperação de áreas degradadas. Revista Árvore, v.36, n.6, p.1099-1118, 2012.

BERTALANFFY, L. V. Teoria geral dos sistemas. Petrópolis: Vozes, 1975.

BERTOL, I. et al. Cobertura morta e métodos de preparo do solo na erosão hídrica em solos com crosta superficial. Revista Brasileira de Ciência do Solo, v.13, n.3, p.373-379, 1989.
BERTOL, I. et al. Relações da rugosidade superficial do solo com o volume de chuva e com a estabilidade de agregados em água. Revista Brasileira de Ciência do Solo, v.30, n.3, p.543-553, 2006.

CASTRO, L. G. et al. Alterações na rugosidade superficial do solo pelo preparo e pela chuva e sua relação com a erosão hídrica. Revista Brasileira de Ciência do Solo, v.30, n.2, p.339-352, 2006.

DAENZER, W. F.; HUBER, F. Systems engineering - methoden und praxis. verbesserte Auflage. Zürich: Verlag Industrielle Organisation, 1994. v.8.

EMPRESA BRASILEIRA DE PESQUISA AGROPECUÁRIA - EMBRAPA. Levantamento de Reconhecimento dos Solos do Estado de Santa Catarina. Rio de Janeiro: 1998. 735p.

EMPRESA BRASILEIRA DE PESQUISA AGROPECUÁRIA - EMBRAPA. Solos do Estado de Santa Catarina. Boletim de Pesquisa e Desenvolvimento, n.46, 2004, 745p.

EMPRESA DE PESQUISAAGROPECUÁRIAE EXTENSÃO RURAL DE SANTA CATARINA EPAGRI. Atlas Climatológico do Estado de Santa Catarina. Florianópolis: 2002.

FINGER, C. A. G. et al. Influência da camada de impedimento no solo sobre o crescimento de Eucalyptus grandis (Hill) ex Maiden. Ciência Florestal, v.6, n.1, p.137-145, 1996.

\section{GABINETE DO PLANEJAMENTO E} COORDENAÇÃO GERAL - GAPLAN. Atlas de Santa Catarina. Rio de Janeiro: Aerofoto Cruzeiro, 1986. p.173.

GONÇALVES, J. L. M. et al. Estabelecimento de reflorestamentos mistos com espécies típicas da Mata Atlântica, em função do cultivo mínimo ou intensivo do solo e do controle de plantas invasoras. Revista Árvore, v.23, n.3, p.259-270, 1999.

GONÇALVES, J. L. M.; STAPE, J. L. Conservação e cultivo de solos para plantações florestais. Piracicaba: IPEF, 2002. 498p.

Revista Árvore, Viçosa-MG, v.37, n.1, p.09-18, 2013 
GUERRA, A. J. T. et al. Erosão e conservação dos solos: conceitos, temas e aplicações. Rio de Janeiro: Bertrand Brasil, 1999.

LEITE, F. P. et al. Crescimento de Eucalyptus grandis em diferentes densidades populacionais. Revista Árvore, v.21, n.3, p.313-321, 1997.

LOPES, M. C. et al. Agrupamento de árvores matrizes de Eucalyptus grandis em função das variáveis dendrométricas e das características tecnológicas da madeira. Ciência Florestal, v.14, n.2, p.133-144, 2004.

LORENZ, E. N. A essência do caos. Brasília: UnB, 1996. 278p.

MARTINS, S. G. et al. Perdas de solo e água por erosão hídrica em sistemas florestais na região de Aracruz. Revista Brasileira de Ciência do Solo, v.27, n.3, p.395-403, 2003.

MELLO, A. H. et al. Estabelecimento a campo de mudas de Eucalyptus grandis micorrizadas com Pisolithus microcarpus (UFSC Pt 116) in sandy soil. Ciência Florestal, v.19, n.2, p.149-155, 2009.

MORA, A. L.; GARCIA, C. H. A Cultura do Eucalipto no Brasil. Eucalypt Cultivation in Brazil. São Paulo: 2000.

MOSER, K. F. et al. The influence of microtopography on soil nutrients in created mitigtion wetlands. Restoration Ecology, v.17, n.5, p.641-651, 2009.

NASCIMENTO, M. I. et al. Eficácia de barreira de eucaliptos na contenção do efeito de borda em fragmento de floresta subtropical no estado de São Paulo, Brasil. Scientia Forestalis, v.38, n.86, p.191-203, 2010.

Revista Árvore, Viçosa-MG, v.37, n.1, p.09-18, 2013
OLIVEIRA, T. K. et al. Radiação solar no subbosque de sistema agrossilvipastoril com eucalipto em diferentes arranjos estruturais. Cerne, v.13, n.1, p.40-50, 2007.

PREVEDELLO, J. Preparo do solo e crescimento inicial de Eucalyptus grandis Hill ex Maiden. em argissolo. 2008. 81f. Dissertação (Mestrado em Engenharia Florestal) - Universidade Federal de Santa Maria, Santa Maria, 2008.

SANTOS, A. F. et al. Doenças do eucalipto no sul do Brasil: identificação e controle. Colombo: Embrapa Florestas, 2001.

SCHÖNAU, A. P. G. Silvicultural considerations for high productivity of Eucalyptus grandis.

Forest Ecology and Management, v.9, n.4, p.295-314, 1984.

SCHUMACHER, M. V.; POGGIANI, F. Caracterização microclimática no interior dos talhões de Eucalyptus camaldulensis Dehnh, Eucalyptus grandis Hill ex Maiden e Eucalyptus torelliana F. Muell, localizados em Anhembí, SP. Ciência Florestal, v.3, n.1, p.9-20, 1993.

SILVEIRA, R. L. V. A. et al. Crescimento e sobrevivência de mudas de eucalipto sob doses de boro cultivadas em condições de viveiro e de campo. Ciência e Agrotecnologia, v.28, n.2, p.366-371, 2004.

TREVISAN, R. et al. Efeito da intensidade de desbaste nas características dendrométricas e tecnológicas da madeira de Eucalyptus grandis. Ciência Florestal, v.17, n.4, p.377-387, 2007.

ZAR, J. H. Biostatistical analysis. 4.ed. New Jersey: Prentice Hall, 1999. 123p. 